\title{
The Relationships between Language Learning Strategies and Positive Emotions among Malay- sian ESL Undergraduates
}

\author{
Mohammad Mohammadipour ${ }^{*}$, Sabariah Md Rashid ${ }^{2}$, Shameem Rafik-Galea ${ }^{3}$, Yap Ngee Thai ${ }^{4}$ \\ 1,2,4 Faculty of Modern Languages and Communication, Universiti Putra Malaysia, Malaysia \\ ${ }^{3}$ Faculty of Social Sciences \& Liberal Arts, UCSI University, Malaysia
}

Corresponding author: Mohammad Mohammadipour, E-mail: M.mohammdipour87@gmail.com

\section{ARTICLE INFO}

Article history

Received: January 10, 2017

Accepted: January 29, 2018

Published: January 31, 2018

Volume: 6 Issue: 1

Conflicts of interest: None

Funding: None

\begin{abstract}
Emotions are an indispensable part of second language learning. The aim of this study is to determine the relationship between the use of language learning strategies and positive emotions. The present study adopted a sequential mixed methods design. The participants were 300 Malaysian ESL undergraduates selected through stratified random sampling from 5 public universities in Malaysia. The quantitative data were collected through two sets of questionnaires: (a) Oxford's (1990) Strategy Inventory for Language Learning (SILL), and (b) Fredrickson's (2009) modified Differential Emotional Scale (mDES). The qualitative data were gathered through semi-structured interviews. With regard to the quantitative data analysis, a series of t-tests and correlational analyses were used. The data from the interviews were analysed qualitatively. A positive significant correlation was found between positive emotions and overall language learning strategy use. Also, the qualitative results of the study indicated that the learners who experienced more positive emotions tended to use a greater variety of language learning strategies. The findings of the study emphasise the importance of students' positive emotions in their use of language learning strategies. It might be suggested that teachers by designing the classroom settings and instructions which promote positive emotions can inspire learners to use language learning strategies more frequently and with a greater variety which in sequence relate to learners' language learning proficiency.
\end{abstract}

Key words: Positive Emotions, Language Learning Strategies, Second Language Learning

\section{INTRODUCTION}

Recently, researchers have shown an increased interest in the processes of language learning. In the same vein, language learning strategies (LLS) which have been defined by Oxford (1990, p. 1) as "specific thoughts, actions, behaviours, steps, or techniques students use to improve their progress in apprehending, internalizing, and using the second language" in and of itself and in relation to heterogeneous variables (e.g., language learning motivation, anxiety, language learning proficiency, etc.) have been thoroughly studied (e.g., Embi, 2000; Lai, 2009; Razak \& Baikkoi, 2014). In this respect, the investigation of the relationship between the frequency of using LLSes and language learning proficiency has remained the main trend of research in this area (Shafie, 2013). However, studies that have attempted to investigate the relationship between the frequency of using LLSes and language learning proficiency have revealed mixed findings. For instance, to determine the possible reasons for the failure to succeed by two less proficient language learners who struggled in their language learning efforts Vann and Abraham (1990) observed the LLSes that they used. The results obtained from the analysis of LLSes showed that the par- ticipants were frequently using LLSes (e.g., attempting to clarify meaning, checking for errors). Nevertheless, these participants were not able to use a sufficient variety of LLSes appropriate for different tasks. In this regard, studies such as that conducted by Frederickson (2001) showed that positive emotions broaden individuals' thoughts and actions repositories. In this light, Frederickson developed a theory called "the broaden-and-build theory of positive emotions" (see. e.g., Fredrickson, 1998; 2001). The present study argues that positive emotions may help individuals to use a wide variety of LLSes which are more appropriate for the tasks during second language learning process.

The broaden-and-build theory (Fredrickson, 2001) hypothesizes that positive emotions broaden individuals' thought-action repertoires. Two studies with 104 university students examined this hypothesis. In both experiments, students watched a video clip which provoked different emotions (i.e., anxiety, neutrality, contentment, amusement, \& anger). The students' thought-action repertoires were examined by means of a Twenty Statements Test. The results of the study showed that positive emotions, relative to a neutral and negative state, broadened the scope of individuals' thought-action repertoires. In this respect, In the light of the 
broaden-and-build theory of positive emotions, the present study attempts to investigate the relationship between positive emotions, variety, and the frequency of the use of LLS.

\section{Statement of the Problem}

Positive emotions are an indispensable part of human behaviour and cognition. Dörnyei (2014) argues that the process of learning a second language is replete with emotions, which can impact students' heterogeneous second language learning factors, such as LLS use. However, regardless of their numerous functions, positive emotions have been abandoned by second language learning studies (Garcia \& Pekrun, 2011; Schutz \& Pekrun, 2007). Specifically, whereas students' negative emotions such as language learning anxiety and stress have been studied extensively, positive emotions have rarely been examined. Also, various studies underlined that positive emotions are related to students' cognition and behaviours (e.g., Cohn \& Fredrickson, 2010; Rusk \& Waters, 2013). In this light, recent developments in second language learning studies have heightened the need for studying positive emotions in and of itself, and in relation to LLS use. Nevertheless, few studies by now have tried to systematically explore the relationship between students' positive emotions and LLS use.

This study is different from the studies done previously on the use of LLSes based on the following points. During the last decade most of the studies in the area of LLSes have mainly focused on the relationship between frequency of the use of LLSes and language learning proficiency (e.g., Kiram, Sulaiman, Swanto, \& Din, 2014; Lai, 2009; Razak \& Baikkoi, 2014). These studies were conducted on the presupposition that more frequent use of LLSes is related to a greater language learning proficiency. However, the findings seem to be mixed. Frequency of the use of LLSes has been verified to have important relationships with English proficiency (Lai, 2009; Mango, 2010; Oxford, 2003). Yet, some studies indicated a different view concerning this result as they demonstrated this association to be somewhat weak and not meticulously demarcated (Borzabadi, 2000; Chik \& Breidbach, 2011; Hong-Nam \& Leavell, 2006). In this regard, the results of previous studies showed that the difference between good and poor language learners in terms of the use of LLSes is not quantitative but qualitative. Lai (2009), for instance, discusses that more proficient students seem to use a greater variety of LLSes in numerous circumstances than do less proficient learners. Similarly, Oxford (2003) argues that proficient language students take mindful steps to understand what they are doing by using a broader range of strategies than less proficient learners do. Similar results have also been reported in a few studies on second language learners (Aliakbari \& Hayatzadeh, 2008; Gerami \& Baighlou, 2011, Mirhassani, Akbari \& Dehghan, 2007). In this respect, Fredrickson (2001) argues that positive emotions broaden individuals' thought-action repositories. In this light, the present study examines the relationship between positive emotions and the use of LLSes in terms of not only the frequency but also the variety of LLS use.

\section{Significance of the Study}

This study is significant for the several contributions it can make to the body of research concerning positive emotions and the use of LLSes. Findings of the study would be useful in addressing theoretical questions and for language pedagogy.

Also, the present study would inspire ESL learners to experience more positive emotions and use additional LLSes, in the language learning process. Also, learners might be enthusiastic to use LLSes more frequently and with a greater variety while they are aware of the benefits of applying LLSes during the language learning process. Mainly, the findings of this study may contribute to the enhancement of learners' awareness of the importance of positive emotions. When learners are aware of the benefits of experiencing positive emotions in their language learning process, they might be encouraged to use affective strategies to enhance the experiences of their positive emotions.

\section{Objectives of the Study}

The major aim of this study was to investigate the relationships between the use of language learning strategies and positive emotions. The specific objectives of this study are as follows:

1. To compare the frequent users and under-users of language learning strategies in terms of the level of positive emotions

2. To determine the relationship between the use of language learning strategies and positive emotions

3. To examine the perceptions of the Malaysian ESL undergraduates on the relationship between positive emotions and the use of various language learning strategies

\section{Research Questions}

Based on the objectives of the study presented earlier, the following research questions were formulated:

1. Is there any significant difference in the positive emotions of Malaysian ESL undergraduate frequent users and under-users of language learning strategies?

2. Is there any significant relationship between the overall use of language learning strategies and positive emotions among Malaysian ESL undergraduates?

3. How do the Malaysian ESL undergraduates perceive their use of various language learning strategies in relation to positive emotions?

\section{LITERATURE REVIEW}

Research on LLSes was initiated by good language learner studies (GLL) (e.g., Rubin, 1975; Stern, 1975). This line of research bloomed in the late 1980s and 1990s and has continued up until now with a richness in theoretical conceptualizations as well as empirical evidence examining the relationship between learners' frequency of LLS use and proficiency level (Embi, 2000; Jalal \& Karev, 2011; Razak \& Baikkoi, 2014). In this concern, the results of literature 
review showed that, although numerous studies have tried to find a relationship between frequency of LLS use and language proficiency, they have presented mixed results.

For example, Carol Mango (2010) investigated the frequency of the use of LLSes of 302 Korean students by applying the Strategy Inventory for Language Learning (SILL) (Oxford, 1990) questionnaire. Also, Mango attempted to examine the differences in the use of LLSes between different proficiency levels and gender. In this respect, a cloze test was applied to asses Learners' proficiency level. The results of the study indicated that proficient learners apply LLSes more frequently than those who are less proficient.

Likewise, a research by Embi, Long and Hamzah (2001) indicated a significant positive relationship between the frequency of LLS use and language performance. The high achievers stated better strategy use than the low achievers. Similarly, Wu (2008) conducted a research on the frequency of the usage of LLSes by learners of diverse levels of proficiency. It was concluded more proficient learners applied LLSes more frequently than less proficient learners.

However, there are studies that have yielded diverse findings from the above cited studies. For example, Borzabadi (2000) studied the relationship among the frequency of the use of LLSes and sex, language proficiency, field of study, and learning styles, and reported that English students were considerably superior in the use of strategies, but no significant relationship was found between the frequency of the use of LLSes and language proficiency, sex, and learning styles. In another study, Ismail and Al Khatib (2013) found that proficiency level had no significant effect on the frequency of the use of strategies. The findings of a study carried out by Hong-Nam and Leavell (2006) revealed that overall the intermediate level learners used more strategies than the advanced or beginner students.

Moreover, the results of previous studies showed that the variance between proficient and less proficient language students in terms of the use of LLSes is not quantitative but qualitative. Lai (2009) argues that GLLs are inclined to use a variety of strategies and can successfully apply them to language tasks. Likewise, in her seminal article, Oxford (2003) argued that GLLs apply a wide variety of LLSes appropriate to different language learning tasks. She further argues that they good language learners can reflect upon their LLSes and apply them to a novel language task. The procedure is conducted effectively in or out of language course, building a more self-directed learner.

Similarly, in their major study, Gerami and Baighlou (2011) compared unsuccessful language learners with those who were successful. They stated that successful learners spend more time on the learning tasks given and had the inclination to employ more various strategies. Mirhassani, Akbari and Dehghan (2007, p. 362) similarly highlighted that "successful learners have a tendency to use a variety of strategies for example considering the language as a rule system, guessing intelligently, finding practice opportunities, and communicating often in the language".

In summary, despite the fact that an excessive number of research studies have been conducted on the relationship between language learners' frequency of the use of LLSes and their proficiency levels, the results seem to be mixed. A critical review of the related literature on the use of LLSes shows that the difference between proficient and less proficient language learners in LLS use is not merely related to the frequency of LLS use. The results of previous studies indicated that proficient learners take mindful steps to comprehend what they are doing by using a broader variety of strategies than less proficient learners. In this regard, Fredrickson (2001) argues that positive emotions generate an ascendant spiral in the direction of emotional well-being by broadening the scope of cognition and actions. In view of all that has been mentioned so far, one may argue that positive emotions relate to frequency, and variety of LLS use. In this regard, the present study examines the relationship between students' positive emotions and language learning strategy use (frequency \& variety).

The theory which is at the cornerstone of present study is Fredrickson's (2001) broaden-and-build theory of positive emotions. In her introduction to broaden-and-built theory of positive emotions, Fredrickson (2001) asserts that definite emotions which are renowned as positive, for instance, pride, joy and love, initiate an ascending spiral to emotional well-being by broadening the scope of actions and cognition. Figure 1 provides a graphic summary of this broaden-andbuild theory of positive emotions.

A significant proposition of Fredrickson's broaden-andbuild theory is that positive emotions carry a flexible value as they reassure "variations in usual behaviour and thought forms" (Fredrickson, 1998, p. 304) by "broadening usual styles of acting or thinking" (Fredrickson, 2001, p. 220). The broaden hypothesis, drawn from the broaden-and-build theory, affirms that positive emotions, comparative to negative emotions and neutral states, widen the range of action, thoughts needs, and precepts that impulsively arise to mind.

Collectively, these studies outline a critical role for positive emotions in individuals' cognitions and behaviours. In this regard, one may suppose that positive emotions might relate to LLS use. So far, however, there has been little discussion about the relationship between positive emotions and LLS use. More specifically, in the light of broaden-andbuild theory of positive emotions, the present study seeks to

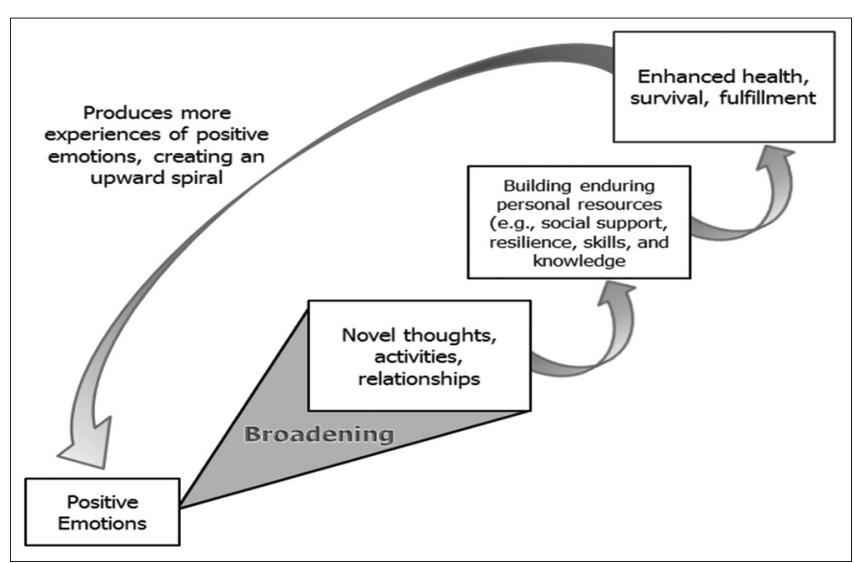

Figure 1. The Broaden-and-Build Theory of Positive Emotions (Source: Cohn \& Fredrickson, 2010) 
address the relationship between positive emotions and the use of LLSes (i.e., overall frequency \& variety).

\section{METHOD}

The present study adopted a mixed method design to shed light on the relationships between positive emotions and LLS use (i.e., frequency \& variety). More importantly, this study adopted a sequential explanatory mixed method design. The sequential explanatory design is a two-phase mixed method design. The first phase is the collection and analysis of quantitative data. Respectively, it is followed by subsequent collection and analysis of qualitative data in the second phase. In the present study, the sequential explanatory mixed method design was employed due to the fact that the quantitative results were substantiated by the qualitative results derived from the data analysis. In this regard, the present study aimed to extend, explore on and refine the quantitative results on the relationship among positive emotions and language learning LLS use.

As shown in Figure 2, the present study was conducted in two phases. Firstly, in order to investigate the relationship between positive emotions and LLSes of Malaysian ESL undergraduates, the data were collected through two questionnaires: Oxford's (1990) Strategy Inventory for Language Learning (SILL) and Fredrickson's (2009) modified Differential Emotional Scale (mDES). In the second phase, the data were collected through interviews due to the fact that they provide a better explanation and understanding of the investigated variables including positive emotions and LLS use. Accordingly, research question three was qualitative in nature. More specifically, in order to determine the relationships between the positive emotions, and variety of LLS use, a qualitative approach was employed. The qualitative data were analysed using the thematic analyses.

\section{Sampling}

The population of this study consisted of Malaysian undergraduates from five different public universities in one state and one federal territory (i.e., Selangor \& Federal Territory of Kuala Lumpur) in Malaysia. Furthermore, the target population of the study consisted of Malaysian undergraduates enrolled in ESL courses in the academic year of 2015-2016 at five public universities. The criterion for choosing the target population was the undergraduate students' obligation to attend the ESL courses. As Ming and Alias (2007, p. 1) argued "in Malaysia, English is a compulsory subject taught to university students regardless of the disciplines they are majoring in".

Tabachnick and Fidell (2001) propose an easy rule of thumb for calculating the sample size: $\mathrm{N}>104+\mathrm{m}$ (where " $\mathrm{N}$ " equals the number of participants, and " $\mathrm{m}$ " stands for the number of predictor variables) for single or individual correlation when only one predictor is used. According to Tebach-nick and Fidell's (2001) formula, the number of participants in the case of 15 predictor variables would be 105 . The sample size in this study was 300 , which far exceeded this number. Therefore, the sample size of this study suggests that its results can be generalized to the whole population. Furthermore, regarding the sample size of the qualitative data, Guest, Bunce, and Johnson (2006) state that a sample of 12 participants is enough to reach data saturation. In this study, the sample for the interviewees involved 30 participants.

With regard to sampling procedure in the present study, first, the researchers equally divided the total population among five universities. Then, the stratified random sampling was carried out for the sampling procedure. It is worth mentioning that the ESL classes at five different universities were conducted based on the students' proficiency levels (i.e., elementary, intermediate, \& advanced). More specifically, the students who scored a band one or two on MUET were classified as elementary proficiency level. The students who scored band three or four were classified as intermediate proficiency level, and the students who scored band five or six were considered as advanced proficiency level. Accordingly, the present study followed the identical classifications for different ESL proficiency levels. Therefore, in the light of stratified random sampling procedure, an equal number of

\begin{tabular}{|l|}
\hline PRIMARY METHOD \\
- QUANTITATIVE \\
- Data Collection: Questionnaires (i.e., Oxford's (1990) SILL, \\
Fredrickson's (2009) mDES) \\
- Data Analysis: t-test, and Pearson Product-Moment Correlation \\
\hline SECONDRY MIETHOD \\
- QUALITATIVE \\
- Data Collection: Interviews \\
- Data Analysis: Qualitative Data Analysis (Typological Analyses \& \\
Thematic Analaysis) \\
\hline INTERPRETATION \\
- Qualitative data were used to explore on, extend, or refine the \\
quantitative results.
\end{tabular}

Figure 2. Procedure in Sequential Explanatory Mixed Method Design 
classes were randomly selected from each proficiency level at each university (i.e., stratum). In total, thirteen classes from three proficiency levels (i.e., one class from each stratum), with 22 to 26 students in each were selected.

Finally, according to the sequential mixed method design, a purposive sampling was used for the qualitative sampling procedure. Initially, 45 students were invited for a face to face interview. They were purposively selected by the researchers from one of the universities which participated in the study on the basis of their second language (L2) language proficiency and their responses to the questionnaires in the initial quantitative stage. Thirty students agreed to participate in the interview. In this way, 21 students with either high or intermediate proficiency and 9 students with low proficiency were selected for the purpose of the interview. Extreme case selection was used to explore the students' strengths and weaknesses in their L2 performance. Extreme cases provide rich and useful information because these cases are somehow unusual or specific in some aspects (Creswell, 2012).

This section describes the participants' social-demographic information. It can be seen in Table 1 that 300 Malaysian ESL undergraduates from five different public universities in Malaysia participated in the study. Out of the 300 students, 60 (20\%) were from University A, 61 (20.3\%) were from University B, 59 (19.6\%) were from University C, 59 (19.6\%) were from University D, and 61 (20.3\%) were from University E. Table 1 shows the students' distribution by university and their classification in terms of the level of English language proficiency, age, and gender. The imbalance between the number of the female and male students in Table 1 is related to the intake of the universities where females dominate.

As shown in Table 1, the data obtained from item five of the demographic section of the questionnaire indicated that from the 300 participating students, $22.76 \%$ attained Band one or two (i.e., the elementary level). This was followed by $34.3 \%$ of the participants who attained Band three or four (i.e., the intermediate level), and $41.9 \%$ of the participants who attained Band five or six (i.e., the advanced level). Moreover, from the 300 participants, $45 \%$ were 19 to 20 years old, $49 \%$ were 21 to 22 years old, and $6 \%$ were 23 to 24 years old.

\section{Instruments}

Two types of instruments were employed in this study: A) two questionnaires: (a) Oxford's (1990) Strategy Inventory for Language Learning (SILL); and (b) Fredrickson's (2009) modified Differential Emotions Scale (mDES); and B) the researcher as an instrument. After the adaptation process of the questionnaires, they were examined by experts in the fields of English Language Teaching and Applied Linguistics. Moreover, all of the questionnaires were translated into the Malay language to ensure validity and to avoid the ambiguity of terms and statements.

The individual items constituting each of the constructs in all of the measuring instruments of this study were subjected to content validity assessment by a panel of experts. The panel of experts was specialized in either the fields of
Table 1. Demographic information of the participants

\begin{tabular}{lcc}
\hline Description & Number $(\mathbf{N})$ & \% of sample \\
\hline University & 60 & 20 \\
A & 61 & 20.3 \\
B & 59 & 19.6 \\
C & 59 & 19.6 \\
D & 61 & 20.3 \\
E & & \\
Gender & 108 & 36 \\
Male & 192 & 64 \\
Female & & \\
MUET & 3 & 0.1 \\
Band score 1 & 68 & 22.66 \\
Band score 2 & 55 & 18.3 \\
Band score 3 & 48 & 16 \\
Band score 4 & 83 & 27.6 \\
Band score 5 & 43 & 14.3 \\
Band score 6 & & 45 \\
Age & 135 & 49 \\
19-20 & 147 & 6 \\
21-22 & 18 & \\
22-24 & & \\
\hline
\end{tabular}

English Language Teaching or Applied Linguistics. They were required to rate each item in terms of its relevance and appropriateness to the underlying construct on a 5-point scale. The average congruence percentage (ACP) involves computing the percentage of items considered to be appropriate and relevant by each expert and then taking a mean of the percentages across experts (Polit \& Beck, 2006). Polit and Beck (2006) recommended that an ACP of $90 \%$ or higher is considered to be acceptable.

The experts' ratings for the items of each construct were also computed and produced overall average ratings for all of the instruments. In this respect, overall, the ratings of the instruments were 4.70 (94\%), 4.67 (93\%), 4.77 (95\%), $4.81(96 \%), 4.78(95 \%)$ and $4.47(89 \%)$ for raters 1 to 6 respectively. The overall inter-rater average was found to be 4.7 (or 94\%). This means that the measuring instruments used to collect the data of this study had satisfactory content validity indices. In addition, the feedback and comments received from the panel of experts were used to establish the necessary clarifications and make changes and modifications during the pilot study.

Furthermore, internal validity is related to how congruent the findings are with reality (Byrne, 2013). In this concern, to augment internal validity of the study, the present study employed member checks. Member checks were used to ensure that the information collected from the interviews and the researchers' interpretations were accurate.

Finally, in order to ensure external validity, this study used thick description which is known to provide enough information and description of the phenomena under study. External validity is concerned with the generalization. That 
is, how generalizable the findings of a study are to other settings. With a rich description of the data and the phenomenon under study, it is expected that the readers would be able to relate the findings of this study to their studies.

A pilot study was conducted to verify the validity of the instrumentation tools and also to find out whether the questionnaires were able to elicit the required information about the learners' positive emotions and the use of LLSes. In particular, in the pilot study, 50 undergraduate university students $($ male $=23$, female $=27$ ) from three proficiency levels (elementary $=18$; intermediate $=16$; advanced $=$ 16) from one of the public universities were selected as the participants. Prior to conducting the pilot study, the participants were given an orientation to the study. Also the students were informed to ask for explanation if required on any item, before responding. In the same vein, they were asked to provide comments and feedbacks which would assist in cultivating the questionnaires.

In addition, it was observed that the participants took a longer time than was expected to answer the questionnaires. This was because of the extra time which was needed to explain each and every question carefully to ensure comprehension of the questions. In spite of the long-time taken to answer the questions (about one hour) the procedure was not too strenuous for the students as they were guided throughout it. This issue enabled them to answer all the questions systematically. Therefore, comprehensibility of the questions by the respondents was ascertained.

Furthermore, twelve students participated in the piloting qualitative study. In this concern, four students from each of the proficiency levels (i.e., advanced, intermediate \& elementary) were selected for the purpose of the interview. By performing a piloting qualitative study, the researchers were able to determine the appropriateness of the interview guide used to elicit the data that was employed to answer the research questions. Besides by handling the interview session the researchers had an experience in transcribing data, analysing them, and interpreting them. This enabled the researchers to see the emerging themes that could be used as a platform in searching for more themes that may emerge from future data. It was also found that when handling different levels of students, the researchers needed to simplify the questions to suit their needs.

\section{The modified differential emotions scale ( $\mathrm{mDES}$ )}

The modified Differential Emotions Scale (mDES) was used in this study to measure the participants' frequency of experiencing overall positive emotions. Fredrickson (2009) developed the mDES to be a comprehensive measure of positive emotions. The mDES uses a trio of emotion adjectives to capture each emotion. Based on the evidence that people are better at recalling peak emotional experiences (Fredrickson, 2001; Fredrickson \& Kahneman, 1993), Fredrickson et al. $(2009$, p. 9) asked respondents to indicate "the greatest amount" that they had experienced "each of the following feelings" based on a four-point Likert-scale (i.e., $0=$ not at all; $1=$ a little bit; $2=$ moderately, $3=$ quite a bit; and 4 = extremely). Occasionally, respondents were asked about the frequency of their experiences, by the question "How often did you feel __ ? (Response options: $0=$ never; $1=$ rarely; $2=$ some of the time; $3=$ often; $4=$ most of the time)". Scoring was centred on making total positive emotion scores or by means of solo items to evaluate particular emotions.

Furthermore, a reliability assessment of the mDES was conducted prior to the use of the questionnaire. For this purpose, Cronbach's alpha was calculated for the mDES by the total sample.

The computations of the reliability checked by Cronbach's alpha revealed a coefficient of.9 for the total sample. A Cronbach's alpha of greater than or equal to.9 ( $\alpha \geq .9)$, indicates that the scale has "excellent" reliability (George \& Mallery, 2003, p. 231).

\section{The strategy inventory for language learning (SILL)}

The second questionnaire which was used in the present study was the version 7.0 of Strategy Inventory for Language Learning (SILL) (Oxford, 1990) which was designed as an instrument for measuring the frequency of the use of LLSes by students. To be specific, the questionnaire has 50 items and is designed for the ESL/EFL learners.

In addition, to determine the reliability of the SILL, the researchers' calculated its Cronbach's alpha value. The computations of the reliability checked by Cronbach's alpha indicated a coefficient of.93 for the total sample which designates that the scale has "excellent" reliability.

\section{The researcher as the instrument}

According to Schwarzer, Bloom land Shono (2006, p. 87) "in qualitative research, it is common to think of the researcher as an instrument, tool, or means of gathering and analyzing data".

In social research, the human instrument can become more reliable through training and practice. Therefore, the researchers had enrolled in various Qualitative Methodology graduate classes to prepare himself as a reliable instrument. Accordingly, the researchers adopted multiple sources and methods in collecting and analysing the data of this study. The use of more than one source or method in data collection and analysis in a study is called triangulation and it is believed to be able to strengthen the reliability of this study as asserted by Merriam (1998) who suggested a few techniques for triangulation. By triangulation, Merriam (1998) refers to the usage of the multiple methods of data collection and analysis.

\section{Data Collection Procedures}

The procedures of data collection are divided into two main categories: quantitative and qualitative data collection. Each of these procedures is explained in the subsequent sections.

Initially, the quantitative data of this study were collected through administering a set of questionnaires (i.e., Oxford's (1990) SILL \& Fredrickson's (2009) mDES) to the sampled respondents in the five sampled universities. The participants 
were assured of the confidentiality and anonymity of their responses. They were also informed that the participation in the study was on a voluntary basis.

Furthermore, the main method used to collect qualitative data in this study was a semi-structured interview. Deemed appropriate to be used in this study, a semi-structured interview was also adopted for its flexibility. The semi-guided questions allowed the researchers the flexibility to ask the respondents questions accordingly. The open-ended questions were designed in advance to elicit detailed and rich data from the students about their positive academic emotions and LLS use. All of the interviews were conducted in English, were recorded, and later transcribed by the researchers.

\section{Data Analysis}

In this study, the quantitative and qualitative data were analyzed separately and, then synthesized at the stage when overall inferences were drawn. The Statistical Package for Social Science software (SPSS), version 22, was used for the quantitative data analysis. The inferential statistics (i.e., correlational analysis, and t-test) was used for the analysis of the data.

For research question one, taking the median-point into account the total scores for LLS were arrived at, and two LLS groups, high and low, were determined. In particular, by a median split procedure based on students' total score on the SILL, all the participants of the study separated in two different groups (i.e., High LLS group or Low LLS group). Henceforward, an independent samples t-test was applied to compare the positive emotions scores for the under-users and frequent users of LLSes.

For question two a series of correlation analyses were run on the relevant data to determine the relationship between the overall LLS use and positive emotions. Specially, Pearson-Product Moment Correlation analyses are used to explain the strength and direction of the linear relationship between the variables of the study. The magnitudes of the associations were determined by using Davis' (1971) scale (see Table 2).

To answer the final research question the data collected by the interviews were qualitatively analysed and interpreted.

\section{RESULTS AND DISCUSSION}

In answering the research questions of the study both the quantitative and qualitative results are presented in accordance with the research questions.

Table 2. Magnitude of association

\begin{tabular}{ll}
\hline Coefficient & Description \\
\hline $0.70-0.99$ & very strong association \\
$0.50-0.69$ & substantial association \\
$0.30-0.49$ & Moderate association \\
$0.10-0.29$ & Low association \\
$0.01-0.09$ & Negligible association \\
\hline
\end{tabular}

\section{The Difference in Positive Emotions of Frequent Users and Under-Users of Language Learning Strategies among Malaysian ESL Undergraduates}

To answer the first research question of this study, based on students' total score on the SILL by a median split procedure, two LLS groups (i.e., frequent users \& under-users), were determined. Henceforth, each participant was categorized into either a frequent LLS users group or an under-users group. In particular, the median score for the LLS use for this sample was 109. Therefore, the participants with scores of 109 and above were considered as frequent users of LLSes and the participants with scores lower than 109 were considered as low under users of LLSes. Furthermore, an independent sample t-test was used to compare the positive emotion scores for frequent users and under-users of LLSes. The t-test analysis revealed a significant difference between the frequent users' scores of LLSes $(M=30.03, S D$ $=18.11)$ and the under-users' scores of LLSes $(M=23.21$, $S D=21.23) t(300)=1.94, p=.00$ (Table 4$)$.

The results of the t-test analysis indicated that there was a significant difference between frequent users and under-users of LLSes in terms of positive emotions at $p<0.05$. As presented in the Table, the mean positive emotions for frequent users of LLSes was more than mean positive emotions for under-users of LLSes. There are numerous potential explanations for this finding, which will be discussed together with the discussion of the present results along with the discussion of the second research question of the study will be presented in the following section of the study.

\section{The Relationship between the Overall Language Learning Strategy use and Positive Emotions}

To find the relationship between the use of LLSes (overall frequency) and positive emotions among Malaysian ESL undergraduates, the Pearson-product-moment correlation was calculated between the overall SILL scores and mDES. Table 5 presents the results of the Pearson-product-moment correlation between the students' overall LLS use and their positive emotions.

Correlation is significant at 0.05 level (2-tailed).

Based on the magnitude of association guidelines $(0.70$ to $0.99=$ very strong association, 0.50 to $0.69=$ substantial association, 0.30 to $0.49=$ moderate association, 0.10 to $0.29=$ low association, \& 0.01 to $0.09=$ negligible association) suggested by Davis (1971), the results presented in Table 5 show that there is a moderate and positive relationship between the students' overall LLS use and their positive emotions $(\mathrm{r}=0.41, \mathrm{n}=300, p<.05)$. These results revealed that the higher frequency of LLS use was associated with the higher students' positive emotions scores. Furthermore, since the $\mathrm{p}$-value ( $p=.000)$ was less than.05, therefore, a statistically significant relationship was revealed between the students' LLS use and their positive emotions.

The correlation between the students' positive emotions and LLS use is interesting because as discussed previously, it was shown that the mean positive emotions for high LLS users was more than those for the low LLS users. The dif- 
Table 4. T-test for Frequent Users and Under-Users of Language Learning Strategies

\begin{tabular}{lccccc}
\hline & \multicolumn{4}{c}{ Language learning Strategy Use } & t- value and significance level \\
\cline { 2 - 6 } & \multicolumn{2}{c}{ Frequent Users } & \multicolumn{2}{c}{ Under-Users } & \\
\hline Total Positive Emotions & Mean & SD & Mean & SD & $\mathrm{t}=1.94$ \\
& 30.03 & 18.11 & 23.21 & 21.23 & $(\mathrm{p}=0.007)$ \\
\hline
\end{tabular}

Table 5. Relationship between students' language learning strategy use and positive emotions

\begin{tabular}{lcr}
\hline Variable & Positive Emotions \\
\hline Overall Language Learning Strategy use & Pearson Correlation & r=0.41 \\
\hline & Sig. (2-tailed) & 0.0 \\
N & 300 \\
\hline
\end{tabular}

Correlation is significant at 0.05 level (2-tailed).

ference between the groups was significant and meaningful, showing that having greater positive emotions is related to the more frequent use of LLS.

To date very little information is found in the literature regarding the relationship between positive emotions and LLS use. In this case, our results are similar to MacIntyre's (2002) findings in that the dissimilarity between the unengaged and engaged students can be enlightened by the emotions they have experienced during the language learning process. The present finding also supports the results of the study by Bolitho et al. (2003) who concluded that students learn in an excellent way while they are affectively involved, and while they eagerly capitalise energy and attention in the learning process.

In theory, these results could be related to the broadening effect of positive emotions. It is a case that "positive emotions, for instance joy, contentment, and interest, have the capacity to broaden individuals' thought-action repertoires" (Fredrickson, 2001, p. 219). These broadened thought-action repertoires in turn build, within individuals, lasting intellectual, physical, and social resources for their future. From this perspective, positive emotions contribute to the continued action or approach behaviour (Fredrickson, 2001). It can be argued that the students who experience positive emotions during learning English actively engage with their learning context and contribute in tasks that may lead to using more LLSes.

In the same vein, the qualitative results of the present study revealed that whilst the students experienced positive emotions, they felt included, satisfied, engaged and committed to learning. As a result, they tended to use LLSes more frequently. For instance, one of the interviewees mentioned that:

when I experience more positive emotions in the classroom, I think I feel more confident and I try to participate in class activities, on the contrary when I feel anxious I try not to participate in learning tasks because I fear of being judged by others and of being embarrassed (Interviewee 14).

In this regard, there are numerous similar responses mentioned by the interviewees, which are discussed further in this section of the study.

The qualitative results of the study showed that experiencing more positive emotions fosters the amount of physical and psychological energy that the student devotes to English language learning, and increases the use of LLSes. In the same way, some of the students stated that effective learning depends on the extent to which students are engaged in the language learning process.

Moreover, the findings of the study showed that///the students who were not engaged reported that they were anxious or bored with learning English and tended to be more passive learners. Some of the students mentioned that the ultimate extent of learning happens when an English language learning class is designed in a way that it encourages students in interaction and active participation. In this regard, one of the interviewees mentioned, "I think I like the English classes which are more fun and I experience more positive emotions there, as the result I try to participate in those classroom activities more, and I use more LLSes" (Interviewee 17). Another student mentioned, "positive emotions make us learn more English, in the same way you use language leaning strategies more often" (Interviewee 24). Similarly, another student declared that, "because I like English language, I use English language and LLSes as far as I can" (Interviewee 27).

Furthermore, another student tried to clarify the relationship between positive emotions and LLS use. In this way, she stated that "as long as we experience positive emotions during learning English, we feel that language learning is not that difficult and its easy, which makes us to learn more and using more LLSes" (Interviewee 26). Another learner had a similar view and asserted that, "if you find English learning boring or it's not good, I don't think you can learn English, or you might use LLSes often, because you have to enjoy it to understand English in my point of you" (Interviewee 23). She also added, "since I enjoy learning English, I feel like to learn more, so whenever I have time, I read English stories, blogs, and so on and so on".

\section{Malaysian ESL Undergraduates' Perceptions on the Relationship between Positive Emotions and the use of Various Language Learning Strategies}

One of the aims of the present study was to elicit the perceptions of the Malaysian ESL undergraduates on the relationship between the positive emotions and the use of 
various LLSes. Although numerous studies have tried to shed light on the relationship between the heterogeneous factors (e.g., anxiety, learning style, proficiency, etc.) and the frequency of LLS use, so far, they have not addressed the relationship between the use of various LLSes and the hypothetical factors. In this regard, this study was designed to illumine the relationship between the positive emotions and the use of various LLSes in the light of Frederickson's (2001) broaden-and-build theory of positive emotions.

Based on the results, the majority of the interviewed students perceived a positive relationship between the positive emotions and the use of various LLSes. For instance, one of the interviewees mentioned that:

we have been learning English by using varaity of strategies, in everyday life, we learn English every time, 24/7, and I am always open to using language learning strategies, since I like English language, and English language has always been my favorite subject (Interviewee 19).

Similarly, another learner remarked that "I think there is no way to understand which LLS works better for you but by using different strategies, I think nobody can do that under the stressful conditions, you should enjoy learning English" (Interviewee 10). Likewise, one of the students stated that "while we enjoy learning English, we can enhance our ability in using English in different ways in life, we also don't separate English from different subjects that we learn so we learn English in different ways" (Interviewee 16). Similarly, one of the students noted that:

with the advancement of technology, I think there are different language leavening strategies that students can use, plus I think learning strategies are highly individualistic and students can see which strategy works better for them, for example, I read a lot in English, and I also spend too much time on transportation services so I listen to English songs on those times. I think most importantly you should enjoy learning English then you will use different strategies to learn English (Interviewee 19).

These findings are broadly in harmony with the results of the study by Rahimi and Bigdeli (2014) who found that the positive emotions can widen the students' scope of cognition, action, and attention. In contrast, negative emotions strengthen the conflicting inclination, limit the amount of the potential language input, and accordingly narrow the students' capacity for learning. Moreover, this result supports Fitzpatrick and Stalikas's (2008) view, that the broadening effect in the broaden-and-build theory can happen as soon as the student expands on the new ideas, has better reconsideration of thoughts or circumstances, defines more advantageous solutions, and integrates new behaviours.

Furthermore, one of the students commented, "I think the more I learn English, the better I feel about English language learning as the result I use English more and I am also more motivated to use different strategies" (Interviewee 20). In this regard, the findings of the present study are also in line with the findings of the study by Fredrickson (2005) who reported that the broaden-and-build theory of positive emotions predicts that positive emotions broaden the scopes of cognition, action and attention, and initiate upward spirals toward increasing emotional well-being.

These findings suggest that having positive emotions is linked to the students' tendency to use LLSes more frequently and to apply a greater variety of LLS. The present study argues that the use of a wide range of LLSes enhances the students' repertoire of the use of LLSes, which in turn helps them to choose appropriate strategies for different tasks. As a result, they are able to choose the LLS which highly matches their learning characteristics and the needs of various tasks. The present study appears to uphold the argument for a change in the focus of the measurement of LLSes from merely focusing on the frequency of LLS use to the use of various LLSes. Moreover, the future research studies of the LLS use might usefully focus on the relationship between the positive emotions and the use of various LLSes in other contexts.

\section{Pedagogical Implications}

The findings of the present study have a number of pedagogical implications. This study provided academic information about the positive emotions and the use of LLSes. The significant relationships among positive emotions, and the use of LLSes emphasize the substantial part that these variables play in the ESL context of Malaysia. Therefore, an instructor has a duty to focus on the learners' positive emotions and use of LLSes along with the ways to manipulate them in order to improve the students' learning performances.

Moreover, the results of the study showed the necessity for implementing strategy training, particularly affective strategies (e.g., mindfulness meditation, positive reappraisal, social sharing of emotions, gratitude exercises \& visualizing the best possible selves) in regular language classes for ESL students. This might be accomplished by the means of course materials and textbooks that stress LLS use, or the general guidebooks on how to turn into a superior language learner.

\section{Contribution of the Study}

The present study has a number of contributions for the field of SLL.

The results of this study specified second language learning research studies have neglected the positive side of human affective life. One underlying implicit assumption seems to be that positive emotions should be less important for theoretical explanations of the humans' thoughts and actions repositories than their negative counterparts (Fredrickson, 2009). Therefore, this study makes a major contribution to research on second language learning by demonstrating the relationship among positive emotions and LLS use. Moreover, it sheds light on the importance of improving individuals' experiences of language learning by helping them to develop and maintain their positive emotions which are necessary for the long-term course of learning a second language.

Furthermore, the present study provides additional evidence regarding Frederickson's (2001) broaden-and-build theory of positive emotions. The main proposition of this 
theory, which is deeply rooted in positive psychology, is that positive emotions broaden individuals' thoughts and actions repertoires. These findings enhance our understanding of positive emotions in second language learning. The contribution of this study is obvious as the results of the study can be employed as guidelines to second language learning. For instance, it might be suggested that teachers by establishing the classroom structure and instruction which promotes exploration, play, and positive emotions can inspire learners to follow a broader array of thoughts and actions and increase their opportunities for peak engagement. Accordingly, the so called learning environment can enhance students' LLS use.

Furthermore, this study is also novel in the sense that, in general, the majority of the related studies on LLSes have focused on the frequency of LLS use, and in particular, they have investigated its relationship to different variables. The findings of this study provide a new understanding of LLS use by examining the relationship between positive emotions and the use of various LLSes. Besides, the qualitative results of the study showed that some of the LLSes mentioned in interviews by the students are not designated in SILL and could be incorporated into the LLS.

\section{CONCLUSION}

The present study found that positive emotions relate to overall frequency and variety of LLS use. Also, the results of the study revealed that the learners' positive academic emotions, and the use of affective strategies do not appear to be an important topic in Malaysian ESL educational context. In this light, there is a need to study the full array of positive and negative emotions in the process of language learning.

Moreover, this study has argued that language learning is a course full of negative and positive emotions. In this light, trying to appreciate and manipulate the learners' emotions is essential to empower language instructors to help their students make their emotions work for them and not against them. The findings of the present study may have several theoretical and pedagogical implications for learners, teachers, and SLL researchers.

The instruments used in this study, that is, the Strategy Inventory for Language Learning (SILL) and modified Differential Emotions Scale (mDES) are not the only instruments for investigating the strategy use, and positive emotions even though they are the frequently used instruments. Therefore, the results were limited to the items of

The findings of the present study support the necessity to use and empirically study more instructive programs that upsurge positive emotions. The ESL studies should move further than the analysis of test anxiety which has been dominant in the past, should study the full variety of the learners' academic emotions, and have to pay more attention to their positive affective experiences than to their negative emotions.

Further examination of the affective LLSes is needed regarding the different types of positive emotion and its effect on academic achievement.

Future studies should also examine how demographic variables affect the experiences of language learners' positive emotions.
The Strategy Inventory for Language Learning (SILL) and modified Differential Emotions Scale (mDES) were the instruments employed to obtain the data and perform the statistical analyses of the present study. Nevertheless, every instrument has its strengths and weaknesses. Therefore, some other instruments could be taken into consideration for further pertinent studies.

\section{REFERENCES}

Aliakbari, M., \& Hayatzadeh, A. (2008). Variation of language strategies among Iranian English students: The effect of gender. International Journal of Pedagogies and Learning, 4(3), 72-87.

Bolitho, R., Carter, R., Hughes, R., Ivanič, R., Masuhara, H., $\&$ Tomlinson, B. (2003). Ten questions about language awareness. ELT journal, 57(3), 251-259.

Borzabadi, D. F. (2000). The relationship between language learning strategies and major field of study, sex, language proficiency, and learning styles ( $\mathrm{PhD}$ Thesis), University of Tehran, Iran.

Chik, A., \& Breidbach, S. (2011). Identity, motivation and autonomy: A tale of two cities. Identity, motivation and autonomy in language learning, 145-159.

Cohn, M. A., \& Fredrickson, B. L. (2010). In search of durable positive psychology interventions: Predictors and consequences of long-term positive behavior change. The journal of positive psychology, 5(5), 355-366.

Creswell, J. W. (2012). Educational research: Planning, conducting, and evaluating quantitative and qualitative research ( $4^{\text {th }}$ ed.). Boston, MA: Pearson

Davis, M. S. (1971). That's interesting! Towards a phenomenology of sociology and a sociology of phenomenology. Philosophy of the social sciences, 1(2), 309-344.

Dörnyei, Z. (2014). The psychology of the language learner: Individual differences in second language acquisition. Mahwah, NJ: Routledge.

Embi, M.A. (2000). Language learning strategies: a Malaysian context. Batu Caves: Fakulti Pendidikan, Universiti Kebangsaan Malaysia.

Fiedler, K. \& Hutter, M. (2013). The Sage Handbook of Applied Memory. Thousand Oaks, CA: Sage

Fitzpatrick, M.R., \& Stalikas, A. (2008). Positive emotions as generators of therapeutic change. Journal of Psychotherapy Integration, 18, 137-154.

Fredrickson, B. L. (1998). What good are positive emotions? Review of general psychology, 2(3), 300-319.

Fredrickson, B.L. (2001). The role of positive emotions in positive psychology: The broaden-and-build theory of positive emotions. The American Psychologist, 56(3), 218-226.

Fredrickson, B. L. (2005). The broaden-and-build theory of positive emotions. In FA Huppert, N. Baylis, B. Keverne (Eds.). The science of well-being, (pp. 803-855). New York: Oxford University Press.

Fredrickson, B. L. (2009). Positivity: Ground breaking research reveals how to embrace the hidden strength of positive emotions, overcome negativity, and thrive. New York, NY: Crown. 
Fredrickson, B. L. \& Kahneman, D. (1993). Duration neglect in retrospective evaluations of affective episodes. Journal of Personality and Social Psychology, 65, 45-55.

George, D., \& Mallery, M. (2003). Using SPSS for Windows step by step: a simple guide and reference $\left(4^{\text {th }} \mathrm{ed}\right)$. Boston, MA: Allyn \& Bacon.

Gerami, M. H., \& Baighlou, S. M. G. (2011). Language Learning Strategies Used by Successful and Unsuccessful Iranian EFL Students. Procedia-Social and Behavioural Sciences, 29, 1567-1576.

Guest, G., Bunce, A., \& Johnson, L. (2006). How many interviews are enough? An experiment with data saturation and variability. Field Methods, 18(1), 59-82.

Hong-Nam K. and Leavell, A. G. (2006). Language Learning Strategy Use of ESL students in an Intensive English Learning Context. System, 34, 399-415.

Ismail, S. A. A., \& Al Khatib, A. Z. (2013). "Investigating the language learning strategies of students in the foundation program of United Arab Emirates University". International Education Studies, 6(9), 35-149.

Jalal, K., \& Karev, J. (2011). The strategy uses frequency of unsuccessful Malaysian language learners and the effect of gender on it. European Journal of Scientific Research, 57(2), 198-205.

Kiram, J. J., Sulaiman, J., Swanto, S., \& Din, W. A. (2014). The relationship between English language learning strategies and proficiency of pre-university students: A study case of UMS. In AIP Conference Proceedings, 1605(1), 775-780).

Lai, C. (2009). Language learning strategy use and English proficiency of university freshmen in Taiwan. TESOL Quarterly, 43(2), 255-280.

Lake, J. (2013). 13 Positive L2 Self: Linking Positive Psychology with L2 Motivation. Language learning motivation in Japan, 71, 225-244.

Linnenbrink-Garcia, L. \& Pekrun, R. (2011). Students' emotions and academic engagement: Introduction to the special issue. Contemporary Educational Psychology, 36(1), 1-13.

Lynn, M. R. (1986). Determination and quantification of content validity. Nursing research, 35(6), 382-386.

McHugh, M. L. (2012). Interrater reliability: The Kappa statistic. Biochemia Medica: Biochemia Medica, 22(3), 276-282.

MacIntyre, P. D. (2002). Motivation, anxiety and emotion in second language acquisition. In P. D. Robinson (Ed.), Individual differences in second language acquisition (pp. 45-68). Amsterdam, Netherlands: John Benjamins

Mango, C. (2010). Korean students' language learning strategies and years of studying English as predictors of proficiency in English, TESOL Journal, 2, 39-61.

Merriam, S. B. (1998). Qualitative Research and Case Study Applications in Education. Revised and Expanded from Case Study Research in Education. San Francisco, CA: Jossey-Bass Publishers
Ming, T. S., and Alias, A., 2007: Investigating readiness for autonomy: a comparison of Malaysian ESL undergraduates of three public universities. Reflections on ELT 6(1), $1-18$.

Mirhassani, A., Akbari, R., \& Dehghan, M. (2007). The relationship between Iranian EFL learners' goal-oriented and self-regulated learning and their language proficiency. TELL, 1(2), 117-132.

Mohamed Amin Embi, Juriah Long, \& Mohd Isa Hamzah. (2001). Language learning strategies employed by secondary school students in Malaysia. Jurnal Pendidikan, 26, 3-20.

Oxford, R. (1990). Language Learning Strategies: What every teacher should know. New York: Newbury House Publishers.

Oxford, R.L. (2003). Language learning styles and strategies: Concepts and relationships. IRAL. 41(4). 271-278.

Polit-O'Hara, D., \& Beck, C. T. (2006). Essentials of nursing research: Methods, appraisal, and utilization (Vol. 1). Philadelphia: Lippincott Williams \& Wilkins.

Rahimi, A., \& Askari Bigdeli, R. (2014). Iranian EFL learners at loggerheads with perceived social support. Iranian Journal of Research in English Language Teaching, 1(3), 31-38.

Razak, N. Z. B. A. \& Baikkoi, M. A. (2014). English language learning strategies of Malaysian secondary school students: Implication for inter-cultural communication. Sociology Mind, 4(2), 206-212.

Rubin, J. (1975). What the Good Language Learner can teach us. TESOL Quarterly, 9, 41-51.

Rusk, R. D., \& Waters, L. E. (2013). Tracing the size, reach, impact, and breadth of positive psychology. Journal of Positive Psychology, 8, 207-221.

Shafie, S. (2013). Language learning strategies used by students preparing for IELTS examination. Journal of Interdisciplinary Research in Education, 3(2), 1-10

Schutz, P. A., \& Pekrun, R. (2007). Emotion in education. San Diego, CA: Elsevier Academic Press.

Schwarzer, D., Bloom, M., \& Shono, S. (Eds.). (2006). Research as a tool for empowerment: Theory informing practice. Charlotte: Information Age Publishing

Stern, H. H. (1975). What can we learn from the good language learner? Canadian Modern Language Review, 31, 304-318.

Tabachnick, B. \& Fidell, L. (2001). Using multivariate statistics. Needham Heights: Allyn \& Bacon.

Byrne, B. M. (2013). Structural equation modeling with LISREL, PRELIS, and SIMPLIS: Basic concepts, applications, and programming. New York: Psychology Press.

Vann R. J. \& Abraham, R. G. (1990). Strategies of unsuccessful learners. TESOL Quarterly, 24, 177-198.

Wu, Y.L. (2008). Language learning strategies used by students at different proficiency levels. Asian EFL Journal, 10(4), 75-95. 